\title{
MODIFIKASI \& OPTIMALISASI IPAL GEDUNG BPPT DENGAN PROSES LUMPUR AKTIF DAN BIOFILTER
}

\author{
Modification \& Optimization WWTP BPPT Building With Activated Sludge And Biofiltration Process
}

Oleh :

Dinda Rita Krishumartani H. \& Setiyono

Pusat Teknologi Lingkungan, BPPT

\begin{abstract}
Abstrak
Sebelum modifikasi IPAL, Gedung BPPT telah memiliki satu instalasi pengolahan air limbah domestik dengan sistem extended aeration menggunakan proses lumpur aktif. Karena kualitas air olahan IPAL saat itu belum memenuhi baku mutu air limbah domestik sesuai dengan Pergub DKI No. 122 tahun 2005, maka perlu dilakukan optimalisasi proses IPAL yang ada. Modifikasi dilakukan agar dapat menghasilkan kualitas air olahan IPAL yang dapat memenuhi standar baku mutu. Modifikasi IPAL ini dilakukan dengan penambahan reaktor biofilter, yang sudah terbukti handal dan stabil dalam hal mengolah air limbah domestik. Berdasarkan hasil monitoring IPAL, maka dapat disimpulkan bahwa sistem ini dapat berfungsi sesuai dengan perencanaan dengan kualitas hasil outlet IPAL yang dapat memenuhi standar kualitas limbah buangan sesuai dengan Pergub DKI No. 122 tahun 2005.
\end{abstract}

Kata Kunci : Air limbah domestik, modifikasi proses, optimalisasi IPAL.

\begin{abstract}
Prior to modification of the WWTP, BPPT building has had a domestic waste water treatment plant with a lagoon aeration system using activated sludge process. Due to the quality of the current WWTP outlet not meet quality standards waste disposal in accordance with the Governor Regulation DKI No. 122 in 2005, it is necessary to optimize the existing WWTP process and needs to be modified in order to produce quality process WWTP outlet that can meet quality standards. WWTP modification is accomplished by the addition of biofilter reactor, which has been proven reliable and stable in terms of treating domestic wastewater. Based on the monitoring results of the WWTP, it can be concluded that this system can function in accordance with the planning of the quality of the WWTP outlet which can meet the quality standards of the waste in accordance with Governor Regulation DKI No. 1222005.
\end{abstract}

Keywords : Domestic wastewater, process modification, WWTP optimization.

\section{PENDAHULUAN}

\subsection{Latar Belakang}

DKI Jakarta merupakan ibu kota negara yang saat ini beban pencemaran khususnya oleh air limbah domestik sangat besar. Saat ini yang sering dituding sebagai biang pencemaran lingkungan adalah pihak industri baik industri besar, menengah maupun industri kecil. Sedangkan untuk industri telah diwajibkan untuk mengolah air limbahnya sebelum dibuang ke perairan umum sampai standar kualitas yang disyaratkan. Sedangkan untuk air limbah domestik, perkatoran dan daerah komersial yang kontribusi pencemaran mencapai sekitar $80 \%$ dari total sumber pencemaran air di DKI Jakarta hanya sekitar $3 \%$ yang telah diolah (PD PAL Jaya, 1996).
Berdasarkan kondisi pencemaran kualitas air di wilayah DKI Jakarta, Pemerintah Propinsi DKI Jakarta telah mengeluarkan Peraturan Gubernur Propinsi Daerah Khusus Ibu Kota Jakarta Nomor 122 Tahun 2005 tentang Pengelolaan Air limbah Domestik di Propinsi Daerah Ibukota Jakarta.

Berdasarkan peraturan gubernur tersebut di atas, pengelolaan Air Limbah Domestik diselenggarakan dengan asas tanggung jawab pemerintah, asas berkelanjutan, asas hak dan kewajiban masyarakat, bertujuan untuk mencegah dan sekaligus menanggulangi pencemaran tanah dan air tanah akibat pembuangan air limbah domestik (black water maupun grey water) yang tidak memenuhi Baku Mutu Air Limbah. Di dalam Pergub DKI Jakarta No. 122 TH. 2005, pada hakekatnya di dalam melakukan pengolahan air limbah domestik tidak mengharuskan menggunakan salah satu 
teknologi tertentu, yang menjadi acuan adalah kualitas air olahan harus memenuhi baku mutu seperti yang telah ditetapkan.

Gedung BPPT di JI. MH. Thamrin, No. 8, Jakarta merupakan salah satu gedung perkantoran yang menghasilkan limbah domestik. Untuk mengolah limbahnya, saat ini gedung BPPT telah dilengkapi dengan 4 buah bak pengumpul limbah dan satu instalasi pengolahan air limbah (IPAL). Tetapi belum semua limbah diolah di dalam IPAL, untuk limbah yang berasal dari floor drain, disalurkan dengan pipa dan langsung dibuang ke saluran umum. Sedangkan limbah dari WC disalurkan ke IPAL, tetapi berdasarkan hasil analisa kualitas limbah, outlet IPAL tersebut belum maksimal.

Parameter amoniak, COD dan BOD masih melebihi standar baku mutu dan secara fisik masih kelihatan keruh dan berbau. Berdasarkan hasil evaluasi pengelolaan dan pengolahan limbah gedung BPPT, yang menjadi permasalahan adalah tidak maksimalnya fungsi beberapa bak pada IPAL eksisting. Agar standar baku mutu dapat tercapai maka diperlukan modifikasi IPAL. Dengan modifikasi ini, nantinya diharapkan semua parameter kualitas limbah akan memenuhi persyaratan sesuai dengan Pergub. DKI no. 122 tahun 2005.

\subsection{Tujuan Penelitian}

Tujuan penelitian ini adalah mengevaluasi dan memperbaiki kinerja sistem pengelolaan air limbah Gedung BPPT sehingga dapat meningkatkan kualitas outlet IPAL agar memenuhi standar kualitas limbah buangan sesuai dengan Pergub DKI No. 122 tahun 2005.

\subsection{Metodologi}

Metodologi yang digunakan dalam kegiatan ini adalah pengumpulan data primer maupun sekunder dan melakukan analisa terhadap data - data tersebut.

Dalam metodologi ini langkah - langkah yang diambil adalah melakukan observasi lapangan dan pengumpulan data - data primer, serta pengambilan data - data sekunder pengolahan limbah gedung BPPT. Setelah data terkumpul, maka dilakukan analisa data untuk mengetahui permasalahan dan cara perbaikannya.

\section{PENGELOLAAN AIR LIMBAH DOMESTIK DI GEDUNG BPPT DAN PERMASALAHANNYA}

\subsection{Karakteristik Air Limbah Domestik}

Air limbah domestik adalah seluruh air buangan yang berasal dari hasil proses kegiatan domestik yang meliputi limbah domestik cair yakni buangan kamar mandi, dapur, air bekas pencucian washtafel atau air limbah hasil kegiatan gedung sehari-hari. Air limbah domestik umumnya mengandung senyawa polutan organik yang cukup tinggi, dan dapat diolah dengan proses pengolahan secara biologis.

Dari hasil analisa kimia terhadap berberapa contoh air limbah domestik yang ada di DKI Jakarta menunjukkan bahwa konsentrasi senyawa pencemar sangat bervariasi misalnya, BOD 31,52 - 675,33 mg/l, ammoniak 10,79 - 158,73 mg/l, deterjen (MBAS) 1,66 - 9,79 mg/l. Hal ini mungkin disebabkan karena sumber air limbah juga bervarisi sehingga faktor waktu dan metoda pengambilan contoh sangat mempengaruhi besarnya konsentrasi.

\subsection{Kondisi Eksisting Pengelolaan Limbah Domestik Gedung BPPT}

Untuk mengelola limbahnya, saat ini Gedung BPPT telah dilengkapi dengan 4 buah bak pengumpul limbah dan satu instalasi pengolahan air limbah (IPAL). Air limbah terutama dari kamar mandi dibagi menjadi dua, yaitu limbah yang berasal dari clean out (CO) dan limbah dari water closed (WC) di salurkan dalam satu pipa tersendiri menuju bak pengumpul. Kemudian dari bak pengumpul ini, limbah dipompa menuji IPAL. Sedangkan limbah yang berasal dari floor drain (FD) disalurkan dengan pipa yang lain dan langsung dibuang ke saluran umum. Jadi saat ini belum semua limbah yang dihasilkan diolah di IPAL. Gambar sistem pengelolaan limbah di area gedung BPPT dapat dilihat pada Lampiran.

Sistem pengelolaan limbah domestik yang digunakan selama ini adalah dengan extended aeration, dimana limbah yang ada dikumpulkan dalam satu bak pengumpul (PIT), kemudian dipompa menuju IPAL dengan sistem perpipaan tertutup. Bak pengumpul/PIT ini juga dapat berfungsi sebagai bak pengendap, yang mana kotoran besar, pasir, dan benda padat lainnya dapat mengendap di PIT ini.

Di IPAL, limbah masuk ke bak ekualisasi, kemudian dari bak ekualisasi limbah dipompa ke dalam reaktor aerasi yang terdiri dari satu ruang besar dan dilengkapi dengan blower udara dan difuser udara yang berada di bagian dasar reaktor. Gambar IPAL eksisting gedung BPPT dapat dilihat pada lampiran.

\subsection{Permasalahan IPAL Eksisting Gedung BPPT}

Beberapa permasalahan yang ada pada IPAL Gedung BPPT antara lain adalah:

a. Limbah yang diolah hanya limbah yang berasal dari clean out (CO) dan water closed (WC) saja, sedangkan limbah lainnya belum diolah sama 
sekali. Dengan demikian maka seharusnya dilakukan perbaikan sistem pengelolaan limbah yang ada saat ini, karena berdasarkan Pergub Provinsi Daerah Khusus Ibukota Jakarta, Nomor 122 Tahun 2005 tentang Pengelolaan Air Limbah Domestik di Provinsi Daerah Khusus Ibukota Jakarta, sistem ini sudah tidak sesuai lagi.

b. Bak Ekualisasi : bak ekualisasi pada hakekatnya berfungsi sebagai bak penampung air limbah dan bak kontrol fluktuasi aliran serta tidak menutup kemungkinan terjadinya dekomposisi organik, akan tetapi kondisi eksisting dilapangan justru sangat kotor. Hal ini terbukti terdapat banyak sampah seperti plastik dan lumpur. Jika hal ini dibiarkan terus menerus maka sampah dan lumpur akan terbawa ke bak aerasi sehingga secara otomatis akan mengganggu proses.

c. Bak Aerasi : Di dalam bak aerasi terjadi proses degradasi zat organik secara aerob yang ada pada air limbah oleh mikroorganisme yang tumbuh dan berkembang dalam keadaan tersuspensi. Oksigen yang dibutuhkan untuk reaksi mikroorganisme tersebut dilakukan dengan cara memasukkan udara ke dalam bak aerasi dengan blower selama 24 jam. Akan tetapi pada kondisi eksisting, injeksi oksigen dilakukan pagi dan sore dengan total hanya \pm 3 jam/hari. Ciri - ciri kegagalan proses aerasi adalah warna air yang hitam pekat dan bau yang menyengat akibat dekomposisi zat organik secara anaerob. Di sisi lain kondisi bak aerasi ditemukan banyak sampah plastik dan lumpur yang berlebih, hal ini dapat mempengaruhi kualitas hasil pengolahan. Jaringan perpipaan blower sudah berkarat dan banyak yang rusak sehingga pengaturan aliran udara tidak merata. Selain itu, kondisi pompa blower juga sudah mulai berkarat, sehingga efisiensi blower sudah mengecil akibat terjadinya kebocoran pipa.

d. Bak Pengendapan : bak pengendapan berfungsi untuk mengendapkan lumpur yang terbawa dari bak aerasi. Didalam bak pengendapan terjadi pemisahan antara air dan padatan secara fisika. Akan tetapi pada kondisi eksisting proses ini dapat dikatakan tidak terjadi karena jumlah lumpur yang berlebih dan harus dibersihkan.

e. Bak klorinasi : kondisi eksisting bak klorinasi sudah tidak difungsikan lagi karena kerusakan pompa.

f. Bak penampung lumpur : kondisi eksisting bak pengendap, bak klorinasi dan bak penampung lumpur tidak dapat dibedakan karena kualitas air secara visual sama, jumlah lumpur yang berlebih dan terdapat sampah plastik.

\section{EVALUASI IPAL EKSISTING DAN MODIFIKASI SISTEM IPAL GEDUNG BPPT}

\subsection{Hasil Evaluasi IPAL Eksisting}

Pada bulan Juni 2010 lalu dilakukan pengambilan sampel limbah untuk di bandingkan antara kondisi fisik dan analisa kualitas limbah segar, dan hasil air olahan. Gambar 1 dan 2 menunjukkan foto - foto pengambilan sampel dan kodisi fisik limbah.

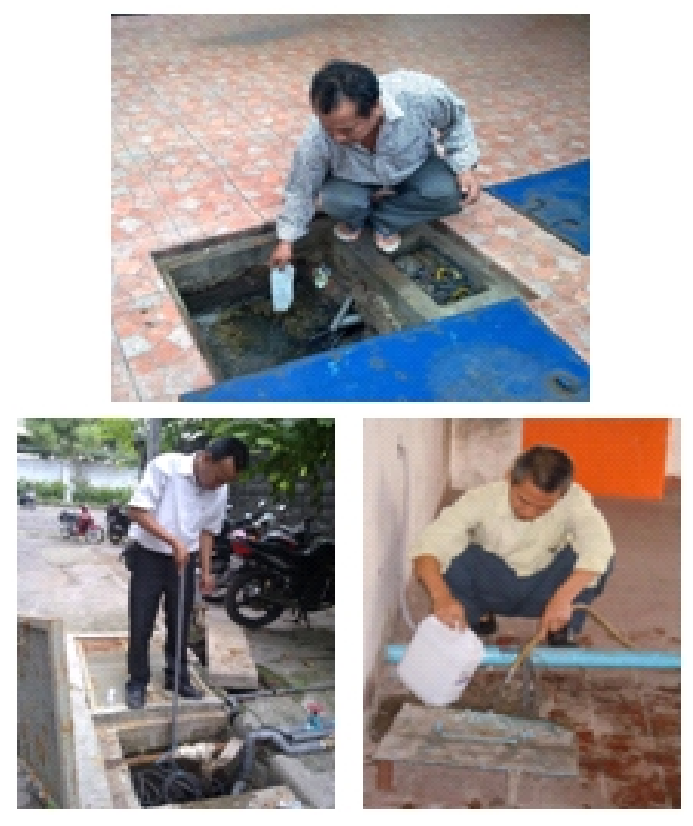

Gambar 1 : Foto Pengambilan Sampel Limbah IPAL Gedung BPPT.

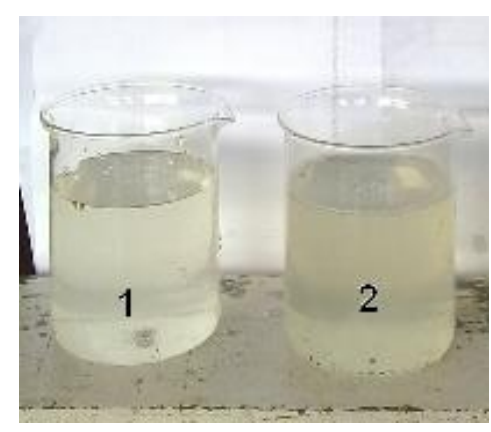

Gambar 2 : Foto Sampel Limbah IPAL ( 1. Limbah Segar; 2. Air Olahan IPAL ).

Hasil analisa lengkap kualitas limbah segar dan hasil outlet olahan limbah di IPAL tersebut dapat dilihat pada Tabel 1 . 
Tabel 1 : Hasil Analisa Limbah IPAL Eksisting (Baku Mutu Berdasarkan Pergub DKI Jakarta No. 122 tahun 2005 tentang Baku Mutu Limbah Cair Domestik).

\begin{tabular}{|c|c|c|c|c|}
\hline \multirow[b]{2}{*}{ Parameter } & \multirow[b]{2}{*}{ Sat } & \multicolumn{2}{|c|}{ Baku Mutu } & \multirow[b]{2}{*}{ Hasil } \\
\hline & & $\begin{array}{c}\text { Rmh } \\
\text { Tangga }\end{array}$ & Komunal & \\
\hline $\mathrm{pH}\left(26^{\circ} \mathrm{C}\right)$ & - & 6-9 & $6-9$ & 7,4 \\
\hline $\mathrm{KMnO}_{4}$ & $\mathrm{mg} / \mathrm{l}$ & 85 & 85 & 39,1 \\
\hline TDS & $\mathrm{mg} / \mathrm{l}$ & 50 & 50 & 20 \\
\hline $\mathrm{NH}_{3}-\mathrm{N}$ & $\mathrm{mg} / \mathrm{l}$ & 10 & 10 & 24,95 \\
\hline Minyak \& Lemak & $\mathrm{mg} / \mathrm{l}$ & 10 & 10 & 7,9 \\
\hline MBAS & $\mathrm{mg} / \mathrm{l}$ & 2 & 2 & 0,28 \\
\hline $\mathrm{BOD}_{5}$ & $\mathrm{mg} / \mathrm{l}$ & 75 & 50 & 29 \\
\hline COD & $\mathrm{mg} / \mathrm{l}$ & 100 & 80 & 85 \\
\hline
\end{tabular}

Berdasarkan hasil evaluasi IPAL dan analisa kualitas limbah tersebut di atas, maka dapat diambil beberapa kesimpulan sebagai berikut :

a. Gedung BPPT belum mengolahan semua limbah yang dihasilkan, sementara berdasarkan Pergub Provinsi DKI Jakarta No. 122 Tahun 2005 telah mewajibkan bahwa semua limbah domestik yang dihasilkan harus diolah terlebih dahulu sebelum dibuang ke saluran umum.

b. Berdasarkan hasil analisa kualitas limbah outlet IPAL BPPT pada tanggal 04 Juni 2010 diketahui bahwa kualitas limbah buangan IPAL BPPT masih belum memenuhi standar buangan air limbah yang sesuai dengan standar yang telah ditetapkan Pemda DKI Jakarta.

c. Untuk mencapai standar pengelolaan dan pengolahan limbah yang sesuai dengan peraturan yang berlaku di DKI, maka perlu dilakukan perbaikan sistem pengelolaan limbah dan modifikasi IPAL yang ada.

\subsection{Modifikasi IPAL Gedug BPPT}

Pemilihan teknologi pengolahan air limbah sangat ditentukan oleh karakteristik air limbah yang akan diolah serta kualitas air olahan yang diinginkan. Pemilihan teknologi yang tepat, disamping akan mendapatkan kualitas hasil olahan yang baik juga akan menghemat biaya operasional IPAL. Kualitas air hasil olahan ditentukan oleh Peraturan Pemerintah setempat dan peruntukan badan air atau sungai dimana air olahan IPAL tersebut akan dibuang. Teknologi pengolahan air limbah yang akan digunakan harus memenuhi beberapa kriteria antara lain :

a. Efisiensi pengolahan dapat mencapai standar baku mutu lingkungan.

b. Pengelolaannya harus mudah.

c. Konsumsi energi sedapat mungkin rendah.

d. Biaya operasinya rendah.

e. Lumpur yang dihasilkan sedapat mungkin kecil. f. Dapat digunakan untuk air limbah dengan beban BOD yang cukup besar.

g. Dapat menghilangkan padatan tersuspensi (SS) dengan baik.

h. Perawatannya mudah dan sederhana.

Untuk meningkatkan kualitas hasil olahan agar dapat memenuhi baku mutu, maka IPAL ini dimodifikasi dengan reaktor biofilter. IPAL lama ini dialih fungsikan sebagai reaktor pengolahan secara lumpur aktif dan bak pengendap. Pertama - tama limbah masuk kedalam reaktor lumpur aktif. Kemudian limbah dialirkan kedalam reaktor sedimentasi. Kedua reaktor tersebut merupakan modifikasi dari IPAL eksisting. Setelah keluar dari reaktor sedimentasi, limbah diolah lebih lanjut dengan menggunakan sistem biofilter.

Kapasitas IPAL yang direncanakan tergantung dari jumlah pemakaian air bersih di gedung BPPT. Asumsi yang digunakan untuk memperkirakan jumlah air limbah domestic adalah $80 \%$ dari jumlah total pemakaian air bersih. Berdasarkan data pemakaian air di gedung BPPT pada tahun 2010, di dapatkan bahwa jumlah peakaian air bersih rata - rata adalah $247,84 \mathrm{~m}^{3} /$ hari.

Dari data pemakaian air di atas, maka perkiraan jumlah air limbah domestik yang akan dihasilkan oleh gedung BPPT adalah sekitar 198,3 $\mathrm{m}^{3} /$ hari ( $80 \%$ dari $247,84 \mathrm{~m}^{3} /$ hari). Jadi kapasitas IPAL yang akan dibangun adalah $200 \mathrm{~m}^{3} /$ hari.

\subsection{Unit - Unit IPAL}

Dari perkiraan jumlah air limbah yang dihasilkan oleh gedung BPPT, maka kapasitas desain yang direncanakan adalah:
a. Kapasitas IPAL
$=200 \mathrm{~m}^{3} /$ hari
b. BOD inlet max
$=350 \mathrm{mg} / \mathrm{l}$
c. Efisiensi Pengolahan
$=75 \%$
d. BOD Air Olahan
$=87,5 \mathrm{mg} / \mathrm{l}$
e. Sistem Operasi
= Semi Otomatis

Sedangkan unit - unit IPAL yang akan digunakan antara lain:

\subsubsection{Bak Ekualisasi}

Karakteristik limbah yang dihasilkan dalam suatu kegiatan pada umumnya tidak akan stabil, dan cenderung naik - turun tergantung dari kegiatan yang sedang berlangsung. Disamping itu jumlahnya juga tidak konstan dan periodik waktunya cenderung tidak terkontrol. Jika dalam proses pengolahan limbah terjadi hal seperti ini, maka akan menyulitkan dalam pengendalian proses, bahkan resiko kegagalan proses dapat terjadi. 
Untuk mengatasi hal-hal seperti tersebut di atas, maka diperlukan adanya suatu bak ekualisasi yang berfungsi untuk menstabilkan karakteristik limbah dan untuk mengontrol debit limbah yang akan masuk ke proses. Jika kondisi pH limbah tidak stabil, di dalam bak ekualisasi ini sering dilengkapi dengan alat $\mathrm{pH}$ kontrol yang akan menstabilkan kondisi $\mathrm{pH}$ sesuai dengan kondisi proses berikutnya yang akan dilakukan.

Bak Ekualisasi bukan merupakan suatu proses pengolahan tetapi merupakan suatu cara / teknik untuk meningkatkan efektivitas dari proses pengolahan selanjutnya. Keluaran dari bak ekualisasi adalah parameter operasional bagi unit pengolahan selanjutnya seperti flow, level/derajat kandungan polutan, temperatur, padatan, dsb.

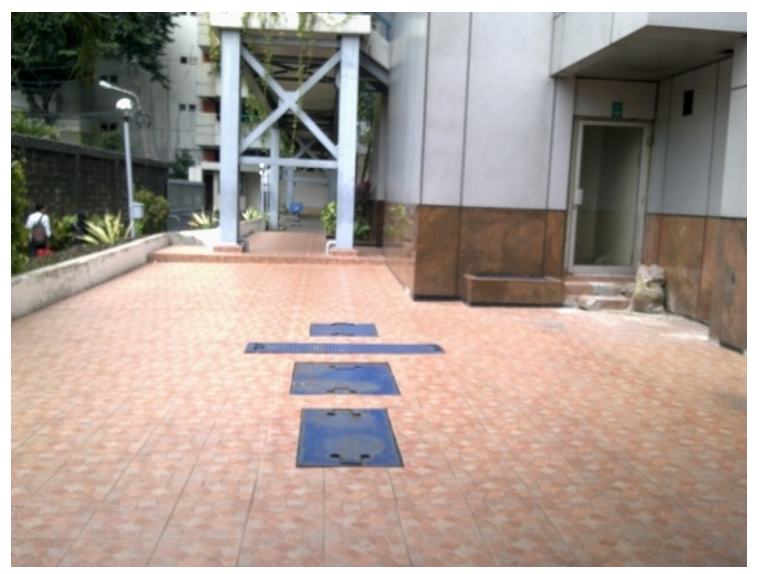

Gambar 3 : Foto Bak Ekualisasi IPAL BPPT.

Kegunaan dari ekualisasi adalah :

a. Mengkontinyukan debit limbah yang akan diolah di IPAL (Membagi dan meratakan volume limbah yang akan masuk pada proses pengolahan di IPAL.

b. Menstabilkan karakteristik limbah (meratakan variable) \& fluktuasi dari beban organik untuk menghindari shock loading pada sistem pengolahan biologi.

c. Meratakan $\mathrm{pH}$ untuk meminimalkan kebutuhan bahan kimia pada proses netralisasi.

d. Meratakan kandungan padatan (SS, koloidal, dII), untuk meminimalkan kebutuhan bahan kimia pada proses koagulasi dan flokulasi (jika diperlukan).

Dilihat dari fungsinya tersebut, unit bak ekualisasi sebaiknya dilengkapi dengan mixer, atau secara sederhana konstruksi / peletakan dari pipa inlet dan outlet diatur sedemikian rupa sehingga menimbulkan efek turbulensi mixing. Idealnya pengeluaran (discharge) dari ekualisasi dijaga konstan selama periode 24 jam, biasanya dengan cara pemompaan maupun cara-cara lain yang memungkinkan.

IPAL BPPT telah dilengkapi dengan satu bak equalisasi, dan sampai saat ini masih berfungsi dengan baik. Untuk bak equalisasi IPAL BPPT tidak dilakukan perubahan, hanya perlu dilakukan pembersihan dari sampah-sampah yang telah menumpuk di dalam saja.

\subsubsection{Screen}

Pada umumnya setiap sistem pengolahan limbah cair mempunyai unit alat penyaring awal / pendahuluan. Proses penyaringan awal ini disebut screening dan tujuannya adalah untuk menyaring atau menghilangkan sampah / benda padat yang besar agar mempermudah proses berikutnya. Dengan hilangnya sampah - sampah padat besar maka transportasi limbah cair pasti tidak akan terganggu, misalnya bila proses transportasi limbah cair diakomodasikan dalam sebuah saluran terbuka atau pun tertutup yang mengalir secara gravitasi, maka tidak akan dijumpai penyumbatan di sepanjang jaringan saluran. Disamping itu, bila limbah cair perlu dipindahkan dengan menggunakan pompa, maka proses screening berfungsi menghilangkan bahan atau benda - benda yang dapat membahayakan atau merusak pompa limbah cair tersebut. Jadi proses screening melindungi pompa dan peralatan lainnya.

Peralatan penyaringan kasar yang biasa digunakan dikenal pula dengan sebutan bar screen atau bar racks. Alat ini biasanya diletakkan pada intake bak penampung limbah cair untuk mencegah masuknya material besar seperti kayu atau daundaunan. Umumnya jarak antara bar yang tersusun pada rack bervariasi antara $20 \mathrm{~mm}$ hingga $75 \mathrm{~mm}$, bergantung pada tingkat kapasitas dan performance unit pompa yang dipakai. Pada keadaan tertentu biasa digunakan pula microstrainer dengan ukuran 15 hingga 64 micrometer dengan tujuan untuk menyaring organisme plankton. Microstrainer biasa digunakan untuk limbah cair dari reservoir pertama (awal). Microstrainer terdiri dari bingkai berbentuk silinder yang ditutup dengan jala terbuat dari kawat tahan karat. Pada saat silinder berputar partikel tersuspensi menempel pada bagian dalam dari permukaan silinder yang kemudian dibersihkan dengan semburan jet air.

IPAL BPPT juga telah dilengkapi dengan satu screen untuk menghindari adanya sampah padat dan benda padat lainnya masuk ke dalam sistem IPAL. Kondisi screen saat ini sudah ada beberapa bagian yang rusak, sehingga perlu dilakukan perbaikan screen saja. Gambar 4 menunjukkan foto lokasi screen yang ada di IPAL BPPT. 


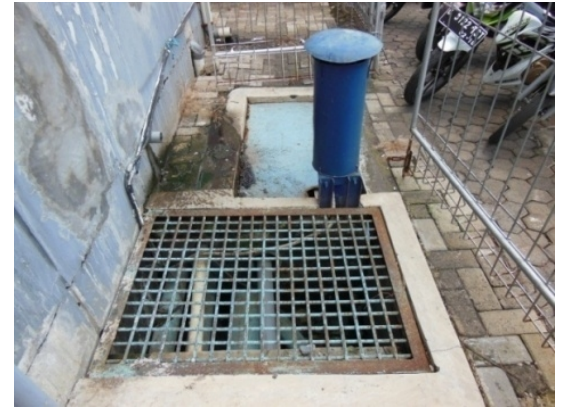

Gambar 4 : Foto Lokasi Screen IPAL BPPT.

\subsubsection{Reaktor Lumpur Aktif}

Reaktor lumpur aktif ini merupakan hasil modifikasi IPAL existing yang ada. Dari semua bak yang ada dimodifikasikan menjadi reaktor lumpur aktif

Berdasarkan hasil evaluasi yang ada, pada awalnya reaktor lumpur aktif ini tidak dapat berfungsi dengan baik. Beberapa perbaikan yang dilakukan di reaktor ini antara lain :

a. Menggantikan semua difuser yang sudah rusak dengan fine buble diffusers.

b. Menggantikan sistem pengaturan distribusi udara yang pada mulanya menggunakan ball valve dengan gate valve yang lebih mudah untuk pengaturan distribusi udara. Dengan gate valve ini, maka akan lebih mudah untuk mendistribusikan aliran udara ke semua area reaktor sehingga proses difusi udara akan lebih sempurna.

c. Memasang sistem sirkulasi lumpur aktif dari bak sedimentasi.

d. Memperbaiki sistem aliran air limbah agar dapat lebih merata.

e. Di bak sedimentasi juga dilakukan perbaikan sistem intake limbah dan menambahkan weir di outlet nya. Dengan adanya perbaikan sistem aliran ini akan dapat menyempurnakan dan mempercepat proses pengendapan lumpur aktif yang ada, sehingga proses sirkulasi lumpur ke reaktor lumpur aktif akan lebih efektif. berikut:

Dimensi reaktor lumpur aktif adalah sebagai
a. Panjang
$: 13,8 \mathrm{~m}$
b. Lebar
: $3,25 \mathrm{~m}$
c. Kedalaman :2,2 m
d. Vol Total : $98,67 \mathrm{~m}^{3}$
e. Waktu Tinggal $: \frac{98,67 \mathrm{~m}^{3}}{200 \mathrm{~m}^{3} / \mathrm{hari}}$
: 0.49 hari $= \pm 12$ jam

\subsubsection{Bak Pengendap}

Sedimentasi adalah suatu unit operasi untuk menghilangkan materi tersuspensi atau flok kimia secara gravitasi. Proses sedimentasi pada pengolahan air limbah umumnya untuk menghilangkan padatan tersuspensi sebelum dilakukan proses pengolahan selanjutnya. Gumpalan padatan yang terbentuk pada proses koagulasi masih berukuran kecil. Gumpalangumpalan kecil ini akan terus saling bergabung menjadi gumpalan yang lebih besar dalam proses flokulasi. Dengan terbentuknya gumpalan-gumpalan besar, maka beratnya akan bertambah, sehingga karena gaya beratnya gumpalan-gumpalan tersebut akan bergerak ke bawah dan mengendap pada bagian dasar tangki sedimentasi.

Bak sedimentasi dapat berbentuk segi empat atau lingkaran. Pada bak ini aliran air limbah sangat tenang untuk memberi kesempatan padatan / suspensi untuk mengendap. Kriteria-kriteria yang diperlukan untuk menentukan ukuran bak sedimentasi adalah: surface loading (beban permukaan), kedalaman bak dan waktu tinggal. Waktu tinggal mempunyai satuan jam, cara perhitungannya adalah volume tangki dibagi dengan laju alir per hari. Beban permukaan sama dengan laju alir (debit volume) rata-rata per hari dibagi luas permukaan bak, satuannya $\mathrm{m}^{3}$ per meter persegi per hari.

Bak pengendap yang direncanakan adalah tipe gravitasi, berbentuk silinder dengan bagian dasar pengendapan berbentuk kerucut yang dilengkapi dengan sistem perpipaan untuk pemisahan lumpur.

Fungsi dari bak ini adalah untuk memisahkan lumpur yang terbentuk dari proses lumpur aktif /anaerobik dari IPAL lama.

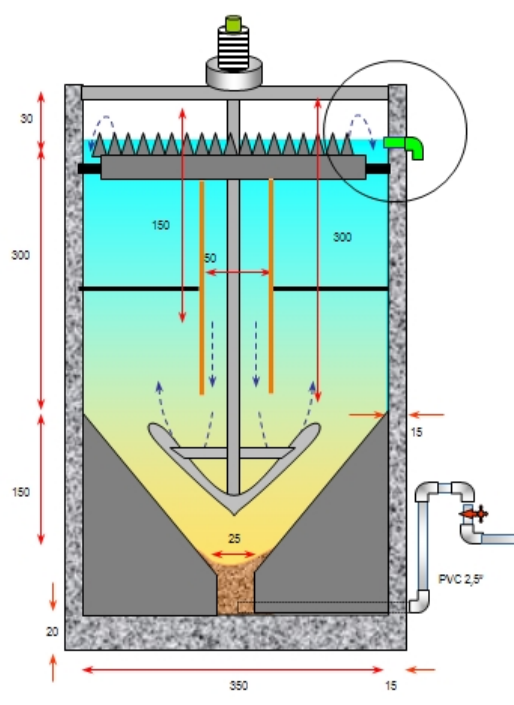

Gambar 5 : Bak pengendap. 
Kriteria perencanaan bak pengendap adalah sebagai berikut:
a. Debit limbah
$=200 \mathrm{~m}^{3} /$ hari
b. Waktu Tinggal
$=8,33 \mathrm{~m}^{3} / \mathrm{jam}$
c. Volume bak
$=2,1 \mathrm{jam}$
$=17,5 \mathrm{~m}^{3}$

Dari kriteria perencanaan di atas, maka diperoleh dimensi bak sebagai berikut:
a. Diameter
$=3,2 \mathrm{~m}$
b. Kedalaman efektif silinder
$=2,6 \mathrm{~m}$
c. Kedalaman efektif kerucut
d. Volume silinder
$=0,75 \mathrm{~m}$
e. Volume kerucut
$=16,0 \mathrm{~m}^{3}$
$=1,5 \mathrm{~m}^{3}$
$=17,5 \mathrm{~m}^{3}$
$=0,25 \mathrm{~m}$
g. Tinggi ruang bebas
$=3,5 \mathrm{~m}$

\subsubsection{Reaktor Biofilter Aerobik}

Untuk meningkatkan kualitas hasil air olahan IPAL ini, sistem proses lumpur aktif IPAL gedung BPPT ini dikombinasi dengan reaktor biofilter/biofilm. Proses yang diterapkan disini adalah proses aerobik, dengan kondisi adanya oksigen terlarut di dalam reaktor air limbah. Pada kondisi aerobik ini, akan terjadi proses nitrifikasi yakni nitrogen amonium diubah menjadi nitrat $\left(\mathrm{NH}_{4}{ }^{+} \rightarrow \mathrm{NO}_{3}\right)$ dan pada kondisi anaerobik terjadi proses denitrifikasi yakni nitrat yang terbentuk diubah menjadi gas nitrogen $\left(\mathrm{NO}_{3} \rightarrow\right.$ $\mathrm{N}_{2}$ ).

Mekanisme proses metabolisme di dalam sistem biofilm secara aerobik secara sederhana dapat diterangkan seperti pada Gambar 6. Gambar tersebut menunjukkan suatu sistem biofilm yang yang terdiri dari medium penyangga, lapisan biofilm yang melekat pada medium, lapisan alir limbah dan lapisan udara yang terletak diluar. Senyawa polutan yang ada di dalam air limbah misalnya senyawa organik (BOD, COD), amoniak, phospor dan lainnya akan terdifusi ke dalam lapisan atau film biologis yang melekat pada permukaan medium.

Pada saat yang bersamaan dengan menggunakan oksigen yang terlarut di dalam air limbah senyawa polutan tersebut akan diuraikan oleh mikroorganisme yang ada di dalam lapisan biofilm dan energi yang dihasilhan akan diubah menjadi biomasa. Suplai oksigen pada lapisan biofilm dapat dilakukan dengan menggunakan blower udara atau pompa sirkulasi.

Biofilter aerobik ini akan mengolah air limbah outlet dari bak pengendap. Biofilter ini merupakan sistem pengolahan lanjut untuk agar limbah dapat memenuhi baku mutu limbah buangan. Skenario pengolahan pada Biofilter Aerob adalah sebagai berikut:
a. Debit Limbah
$=200 \mathrm{~m}^{3} /$ hari
b. BOD masuk
$=100 \mathrm{mg} / \mathrm{l}$
c. Efisiensi
$=75 \%$
d. BOD keluar
$=25 \mathrm{mg} / \mathrm{l}$

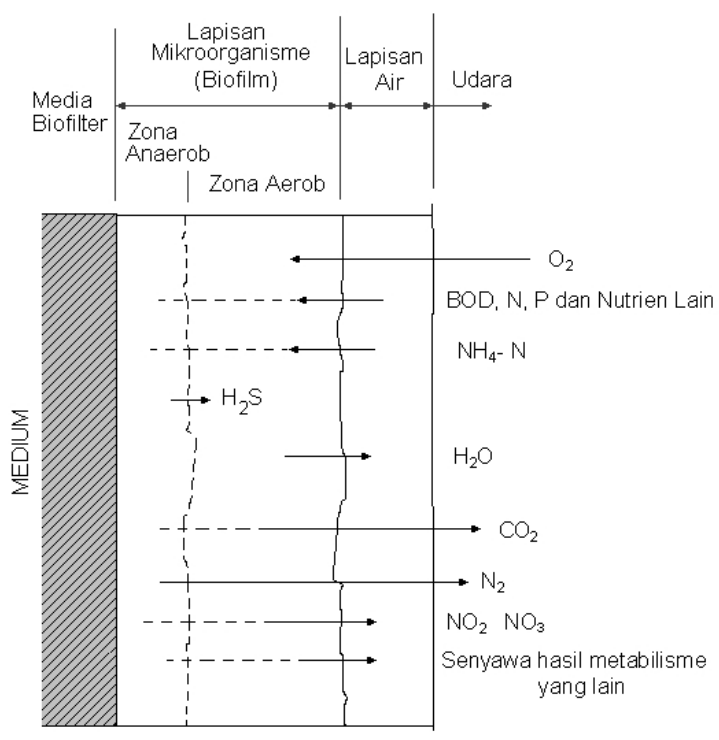

Gambar 6 : Mekanisme Proses Metabolisme Di Dalam Proses Dengan Sistem Biofilm (Eckenfelder,1989).

Dari krieria tersebut di atas, maka diperoleh dimensi reaktor aerobik adalah sebagai berikut:
a. Lebar
$=3,5 \mathrm{~m}$
b. Kedalaman efektif
$=2,6 \mathrm{~m}$
c. Panjang efektif
$=10,0 \mathrm{~m}$
d. Tinggi ruang lumpur
$=0,4 \mathrm{~m}$
e. Tinggi ruang bebas
$=0,4 \mathrm{~m}$
f. Tinggi bed media biakan
$=1,6 \mathrm{~m}$

Ruang pada reaktor biofilter dibagi menjadi 2, dan ditambah dengan 2 ruang aerasi.

$$
\begin{array}{ll}
\text { Panjang ruang aerasi } & =2 \times 0,75 \mathrm{~m} \\
& =1,5 \mathrm{~m}
\end{array}
$$
lampiran.

Gambar reaktor biofilter aerobik dapat dilihat pada

\subsubsection{Bak Pengendap Akhir}

Bak pengendap akhir berfungsi untuk mengendapkan mikroba pengurai. Setelah mengendap, bakteri tersebut kemudian disirkulasi kembali ke dalam reaktor biofilter aerob.

Kriteria pengolahan bak pengendap akhir adalah sebagai berikut:
a. Debit Limbah : $200 \mathrm{~m}^{3} /$ hari
b. BOD masuk $: 25 \mathrm{mg} / \mathrm{l}$
c. Efisiensi :5\%
d. $\quad$ BOD $_{\text {keluar }}: 23,8 \mathrm{mg} / \mathrm{l}$ 
Dari kriteria pengolahan di atas, maka diperoleh dimensi bak pengolah akhir adalah sebagai berikut:

$\begin{array}{lll}\text { a. Lebar } & =3,5 \mathrm{~m} \\ \text { b. } & \text { Kedalaman Efektif } & =2,4 \mathrm{~m} \\ \text { c. } & \text { Panjang Efektif } & =1,5 \mathrm{~m} \\ \text { d. } & \text { Tinggi Ruang bebas } & =0,6 \mathrm{~m}\end{array}$

\subsection{Peralatan dan Pelengkap IPAL}

\subsubsection{Media Pembiakan Mikroba}

Salah satu media biofilter yang banyak digunakan, yakni media dalam bentuk sarang tawon (honeycomb tube) dari bahan PVC. Kelebihan dalam menggunakan media plastik tersebut antara lain :

a. Mempunyai luas permukaan per $\mathrm{m}^{3}$ volume sebesar $150-240 \mathrm{~m}^{2} / \mathrm{m}^{3}$.

b. Volume rongga yang besar dibanding media lainnya.

c. Kemungkinan terjadinya penyumbatan pada media sangat kecil (Eckenfelder,1989).

Media biofilter sarang tawon termasuk hal yang penting, karena media ini berfungsi sebagai tempat tumbuh dan menempelnya mikroorganisme. Dua sifat yang paling penting yang harus ada dari media adalah sebagai berikut:

a. Luas permukaan dari media yang cukup besar per satuan volume.

b. Persentase ruang kosong yang baik, karena semakin besar ruang kosong, akan semakin besar pula kontak biomassa yang menempel pada media pendukung dengan substrat yang ada dalam air buangan.

Untuk mendapatkan permukaan media yang luas, media dapat dimodifikasikan dalam berbagai bentuk, yaitu bergelombang, saling silang seperti sarang tawon. Gambar 7 menunjukan media sarang tawon yang dipakai di reaktor biofilter IPAL BPPT.

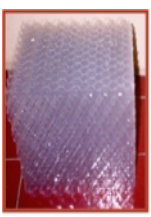

Media Baru

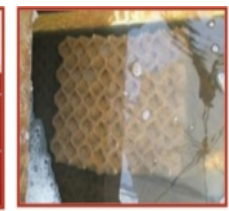

Media di Dalam
Reaktor

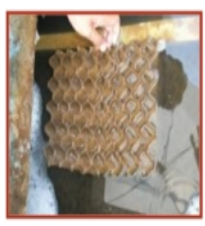

Media diambil dari

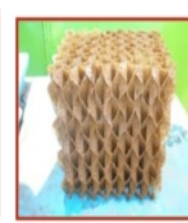

Media dikeluarkan dan
Gambar 7 : Media Biofilter Sarang Tawon.

Spesifikasi media biofilter yang digunakan :
a. Material
: PVC sheet
b. Ukuran Modu
: $25 \mathrm{~cm} \times 30 \mathrm{~cm} \times 30 \mathrm{~cm}$
c. Ketebalan
: 0,15-0,23 mm
d. Luas Kontak Spesifik
: $200-226 \mathrm{~m} 2 / \mathrm{m} 3$
e. Diameter lubang
: $2 \mathrm{~cm} \times 2 \mathrm{~cm}$
f. Warna
: transparan.
g. Berat Spesifik
: $30-35 \mathrm{~kg} / \mathrm{m3}$

h. Porositas Rongga :0,98

i. Jumlah total media yang dibutuhkan $=50 \mathrm{~m}^{3}$

\subsubsection{Pompa Air Limbah}

Fungsi : Untuk mentransfer limbah dari bak equalisasi ke IPAL

Jumlah : 2 (dua) buah

Spesifikasi Pompa yang digunakan:
a. Kapasitas
$=300$ liter $/$ menit
b. Total Head
$=16,0 \mathrm{~m}$
c. Output listrik
$=0,75 \mathrm{k}$. Watt, 380 volt
d. Bahan
$=$ tahan karat.
e. Merk
$=$ Ebara
f. Model
$=50$ DVSA 5.75 (3 phase)
g. Jumlah

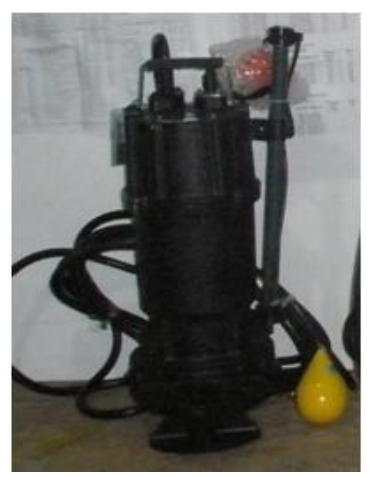

Gambar 8 : Foto pompa submersibel merk Ebara type DVSA 5.75

\subsubsection{Pompa Air Sirkulasi}

Spesifikasi Pompa :

a. Rasio Sirkulasi Hidrolik (Hydraulic Recycle ratio, HRT)

$: 0,3-0,75$

b. Laju Sirkulasi $\quad: 400 \mathrm{m3} /$ hari $: 280 \mathrm{It} / \mathrm{menit}$

c. Kapasitas : $300-500$ liter per menit

d. Total Head : $16 \mathrm{~m}$

e. Output listrik : 3,7 k.Watt, 380 volt

f. Bahan : tahan karat.

g. Merk : HCP.

h. Model :AF-35A. (3 phase)

i. Jumlah :2 buah.

\subsubsection{Water Meter}

Untuk melengkapi sistem kontrol dan monitoring sistrem operasional IPAL, maka pada outlet IPAL tersebut dipasang water meter. Ada beberapa fungsi water meter ini antara lain :

a. sebagai alat bantu sistem kontrol debit proses agar IPAL dapat berfungsi dengan baik.

b. Sebagai alat monitoring debit limbah yang terolah setiap harinya guna kontrol kapasitas IPAL. 
c. Sebagai alat monitoring untuk penyusunan laporan rutin jumlah pembuangan limbah ke lingkungan.

Spesifikasi Water Meter adalah sebagai berikut:
a. Material
$=$ Mild steel
b. Type
$=$ Rotary
c. Diameter
d. Sist pembacaan
$=4^{\prime \prime}$
$=$ analog

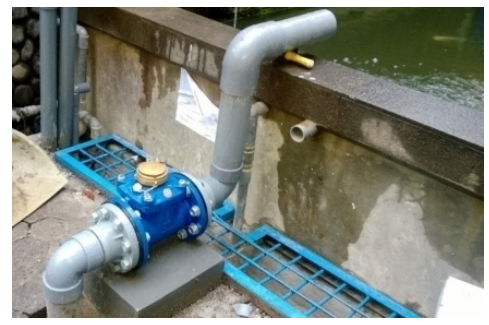

Gambar 9 : Foto Flow Meter untuk IPAL BPPT.

\subsubsection{Desinfektan}

Proses pengolahan secara kimia yang ada disini adalah proses disinfektan, yaitu proses penghancuran atau pembunuhan mikroorganisme penyebab penyakit (pathogen). Proses ini pada umumnya merupakan proses pada tahap akhir dalam satu rangkaian proses pengolahan air limbah sebelum disalurkan / dibuang ke saluran umum.

Metode yang paling banyak digunakan adalah metode penambahan bahan kimia, seperti yang diterapkan di IPAL gedung BPPT. Disinfektan yang diterapkan adalah dengan penggunaan zat khlor (khlorinasi) dengan chlor tablet. Gambar 10 menunjukkan tabung khorinator yang digunakan di IPAL gedung BPPT.

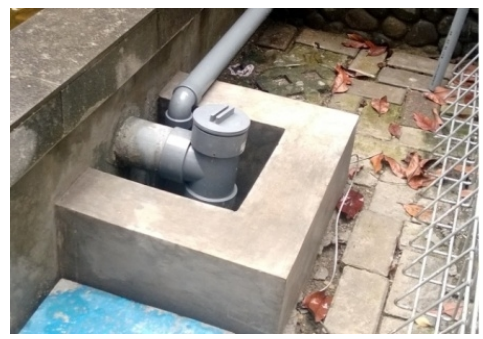

Gambar 10 : Tabung Klorinasi Dengan Kaporit Tablet.

\section{MONITORING KINERJA IPAL GEDUNG BPPT}

Setelah pelaksanaan pekerjaan renovasi atau modifikasi IPAL selesai dikerjakan, maka dilakukan pekerjaan start-up operasional dan monitoring kinerja dari IPAL tersebut. Monitoring hasil olahan ini dilakukan untuk pengecekkan terhadap sistem operasi IPAL. Jika dari hasil monitoring tersebut masih ditemukan hal-hal yang menyebabkan kurang dalam sistem operasi IPAL maupun kualitas outlet yang belum sesuai dengan perencanaan sebelumnya, maka akan dilakukan penyempurnaan penyempurnaan yang berkaitan dengan sistem operasinal IPAL. Pekerjaan ini juga mencakup sampling hasil dan analisa hasil pengolahan. Foto hasil monitoring dan hasil analisa limbah disajikan seperti Pada Gambar 11 sebagai berikut.

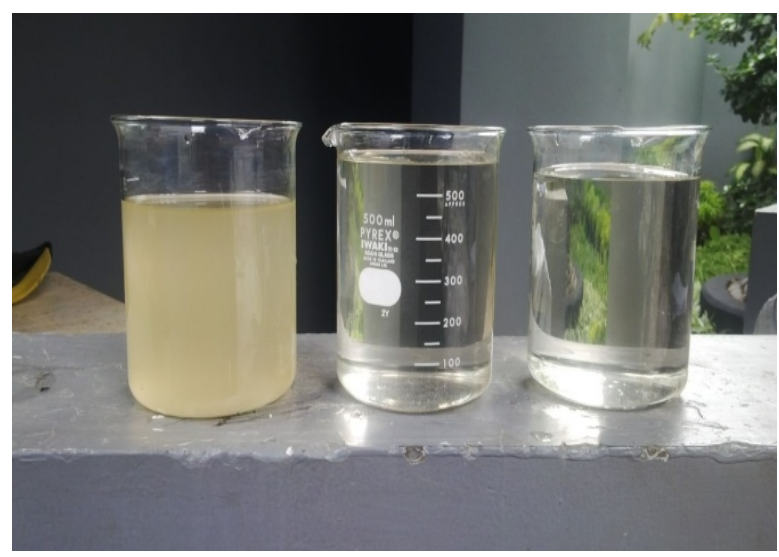

Gambar 11 : Foto Kualitas Inlet Dan Outlet Reaktor Lumpur Aktif dan Outlet Reaktor Biofilter.

Monitoring kenerja dari IPAL ini dilakukan setiap hari secara visual, dan secara periodik hasilnya dianalisakan ke laboratorium lingkungan yang terakreditasi. Tabel 2 menunjukkan hasil analisa laboratorium kualitas air limbah hasil olahan IPAL gedung BPPT setelah dilakukan dilakukan renovasi dan modifikasi IPAL.

Tabel 2: Hasil Analisa Laboratorium Air Limbah IPAL Gedung BPPT Tanggal sampling 19 Juni 2014 (Baku Mutu Berdasarkan Pergub DKI Jakarta No. 122 tahun 2005 tentang Baku Mutu Limbah Cair Domestik).

\begin{tabular}{|l|c|c|c|c|}
\hline \multirow{2}{*}{ Parameter } & \multirow{2}{*}{ Sat } & \multicolumn{2}{|c|}{ Baku Mutu } & \multirow{2}{*}{ Hasil } \\
\cline { 3 - 4 } & & $\begin{array}{c}\text { Rmh } \\
\text { Tangga }\end{array}$ & Komunal & \\
\hline $\mathrm{pH}\left(26^{\circ} \mathrm{C}\right)$ & - & $6-9$ & $6-9$ & 6,9 \\
\hline $\mathrm{KMnO}_{4}$ & $\mathrm{mg} / \mathrm{l}$ & 85 & 85 & 12,5 \\
\hline $\mathrm{TDS}$ & $\mathrm{mg} / \mathrm{l}$ & 50 & 50 & 7 \\
\hline $\mathrm{NH}_{3}-\mathrm{N}$ & $\mathrm{mg} / \mathrm{l}$ & 10 & 10 & 14,88 \\
\hline Minyak \& Lemak & $\mathrm{mg} / \mathrm{l}$ & 10 & 10 & $<0,2$ \\
\hline $\mathrm{MBAS}^{\mathrm{n}}$ & $\mathrm{mg} / \mathrm{l}$ & 2 & 2 & 0,03 \\
\hline $\mathrm{BOD}_{5}$ & $\mathrm{mg} / \mathrm{l}$ & 75 & 50 & 22 \\
\hline $\mathrm{COD}$ & $\mathrm{mg} / \mathrm{l}$ & 100 & 80 & 7 \\
\hline
\end{tabular}

Dari hasil tersebut di atas, maka dapat disimpulkan bahwa semua parameter telah memenuhi baku mutu limbah cair domestik, sesuai Peraturan Gubernur DKI Jakarta No. 122 tahun 2005 


\section{KESIMPULAN}

Berdasarkan hasil analisa kualitas limbah IPAL gedung BPPT dan monitoring operasional harian yang dilakukan di atas, maka dapat diambil beberapa kesimpulan, sebagai berikut :

a. Kombinasi teknologi pengolahan limbah dengan proses lumpur aktif dan biofilter dapat digunakan untuk mengolah limbah domestik dengan baik.

b. Dengan teknologi Biofilter, hasil outlet IPAL ini akan lebih stabil.

\section{DAFTAR PUSTAKA}

- Annonim 1, "The Studi On Urban Drainage and Wastewater Disposal Project in The City of Jakarta"., JICA, 1990.
- Annonim 2, "Peraturan Gubernur Daerah Khusus Ibukota Jakarta, Nomor 122 Tahun 2005, Tentang Pengelolaan Limbah Domestik di Provinsi Daerah Khusus Ibukota Jakarta."

- Eckenfelder W. Weslwy,"Industrial Water Pollution Kontrol", Second Edition, McGrawHill Book Company. 1989.

- PTL "Laporan Modifikasi IPAL Gedung BPPT", Pusat Teknologi Lingkungan, Jakarta 2010.

- Said, N.I, 2008, "Pengolahan Air Limbah Domestik di DKI Jakarta", Pusat Teknologi Lingkungan, Deputi Bidang Teknologi Pengembangan Sumberdaya Alam Badan Pengkajian dan Penerapan Teknologi. 


\section{LAMPIRAN}

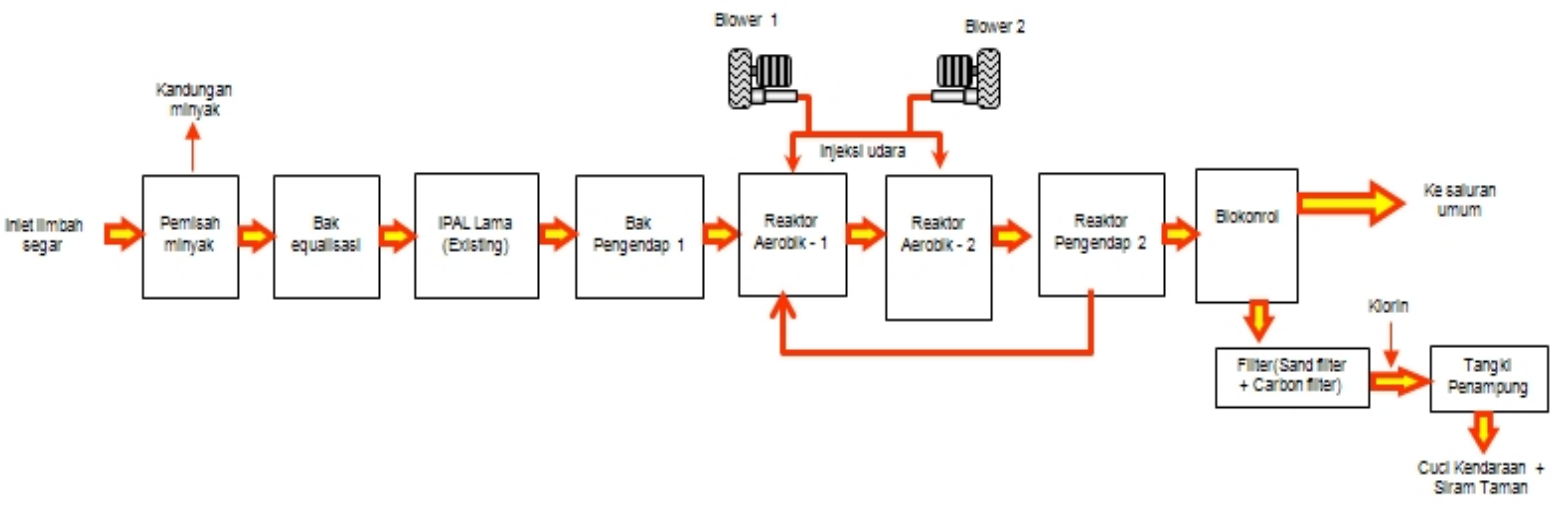

Gambar A : Proses IPAL BPPT setelah modifikasi.
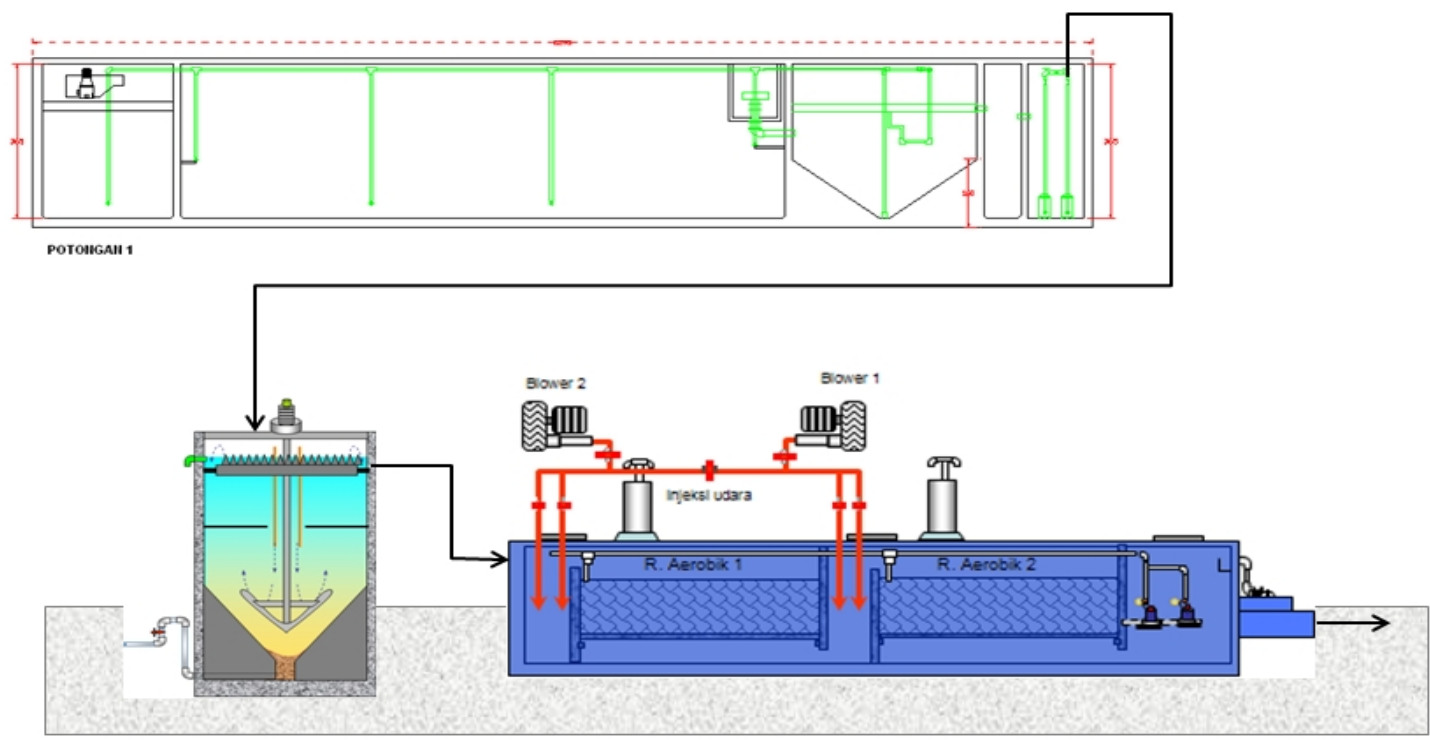

Gambar B : Diagram Alir Proses Pengolahan limbah di IPAL BPPT setelah modifikasi.

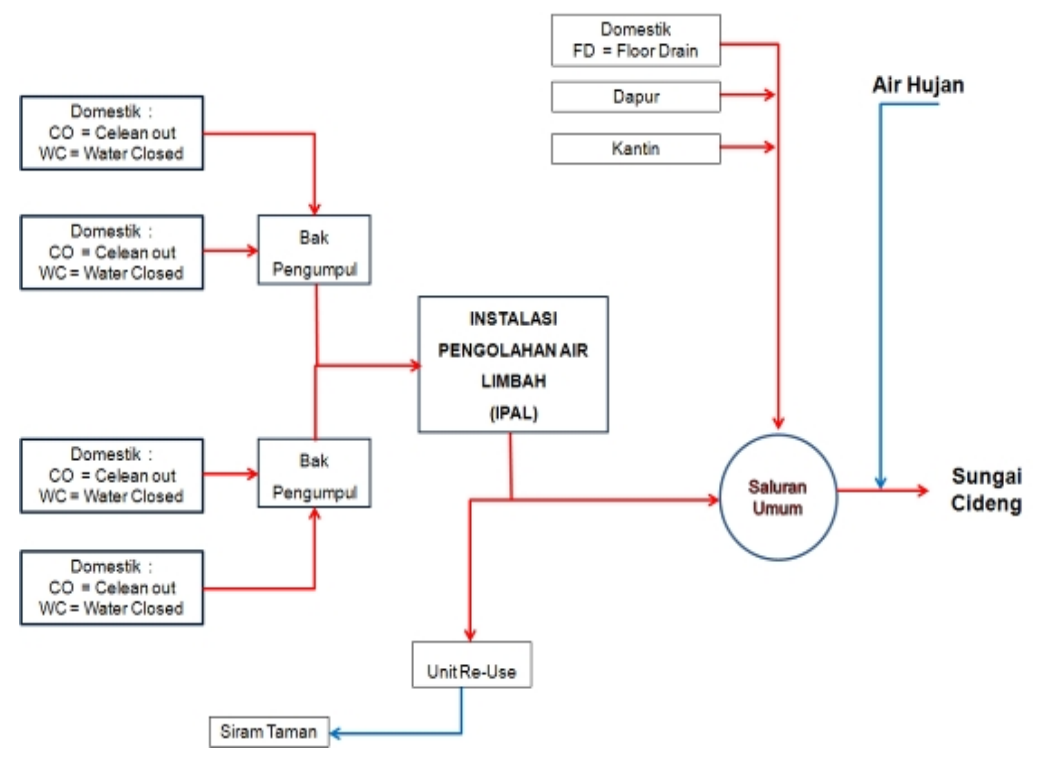

Gambar C : Sistem Pengelolaan Limbah eksisting di Area Gedung BPPT. 


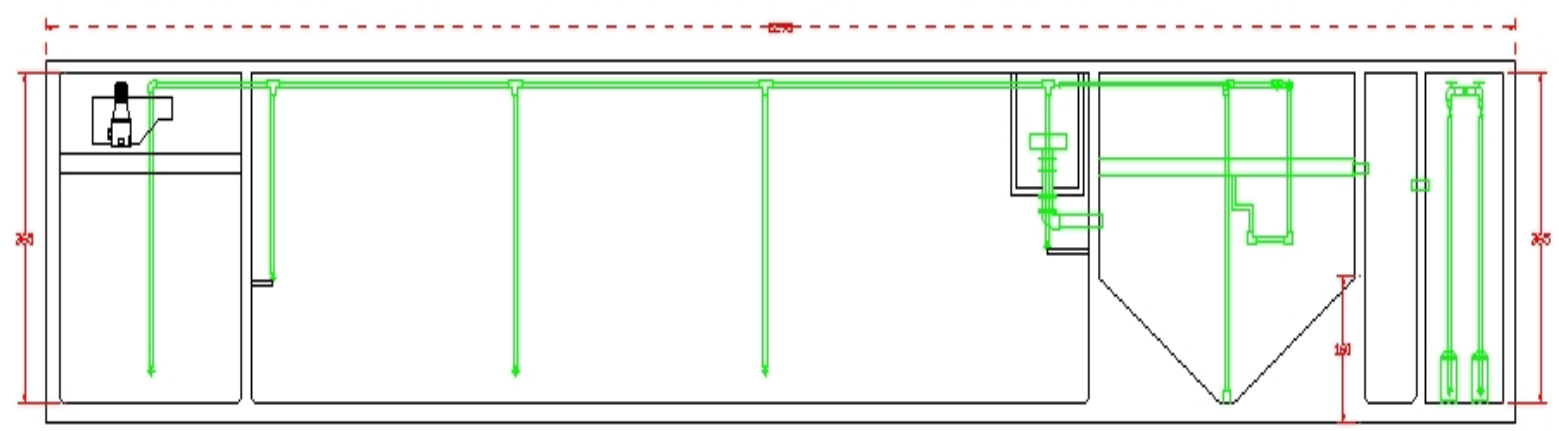

POTOIIGAII 1

Gambar D : Gambar Potongan IPAL Eksisting Gedung BPPT.

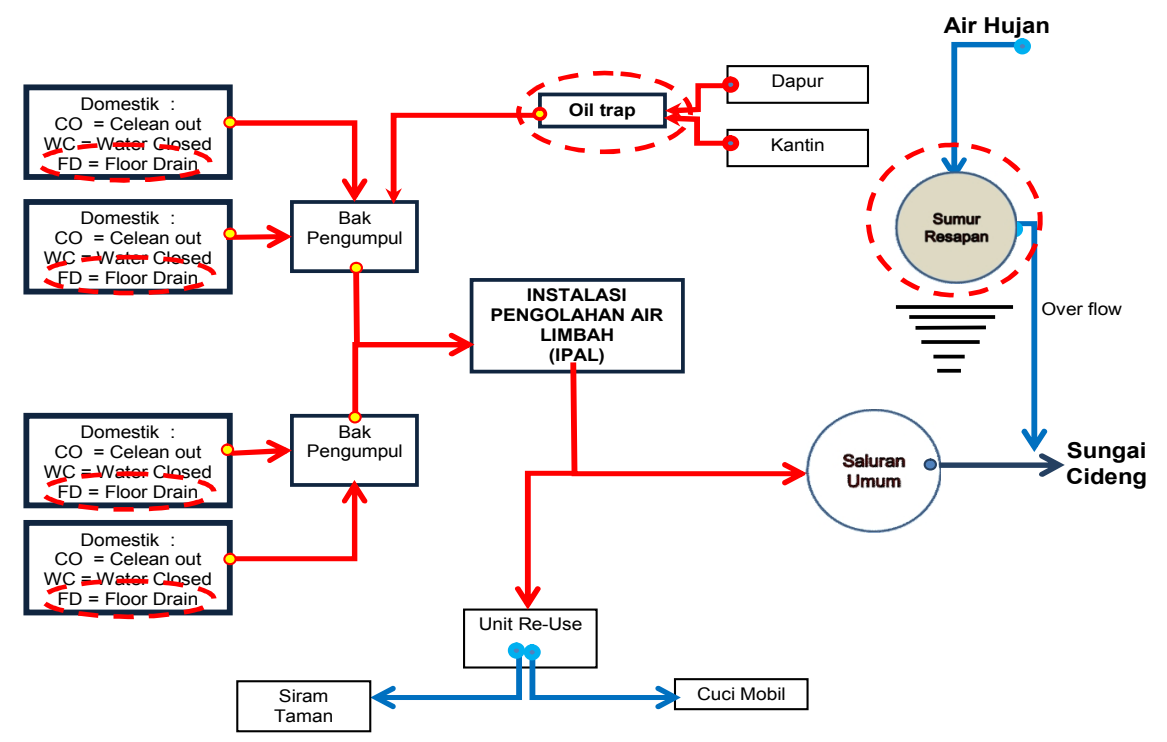

Gambar E : Perbaikan Sistem Pengelolaan Limbah Gedung BPPT.
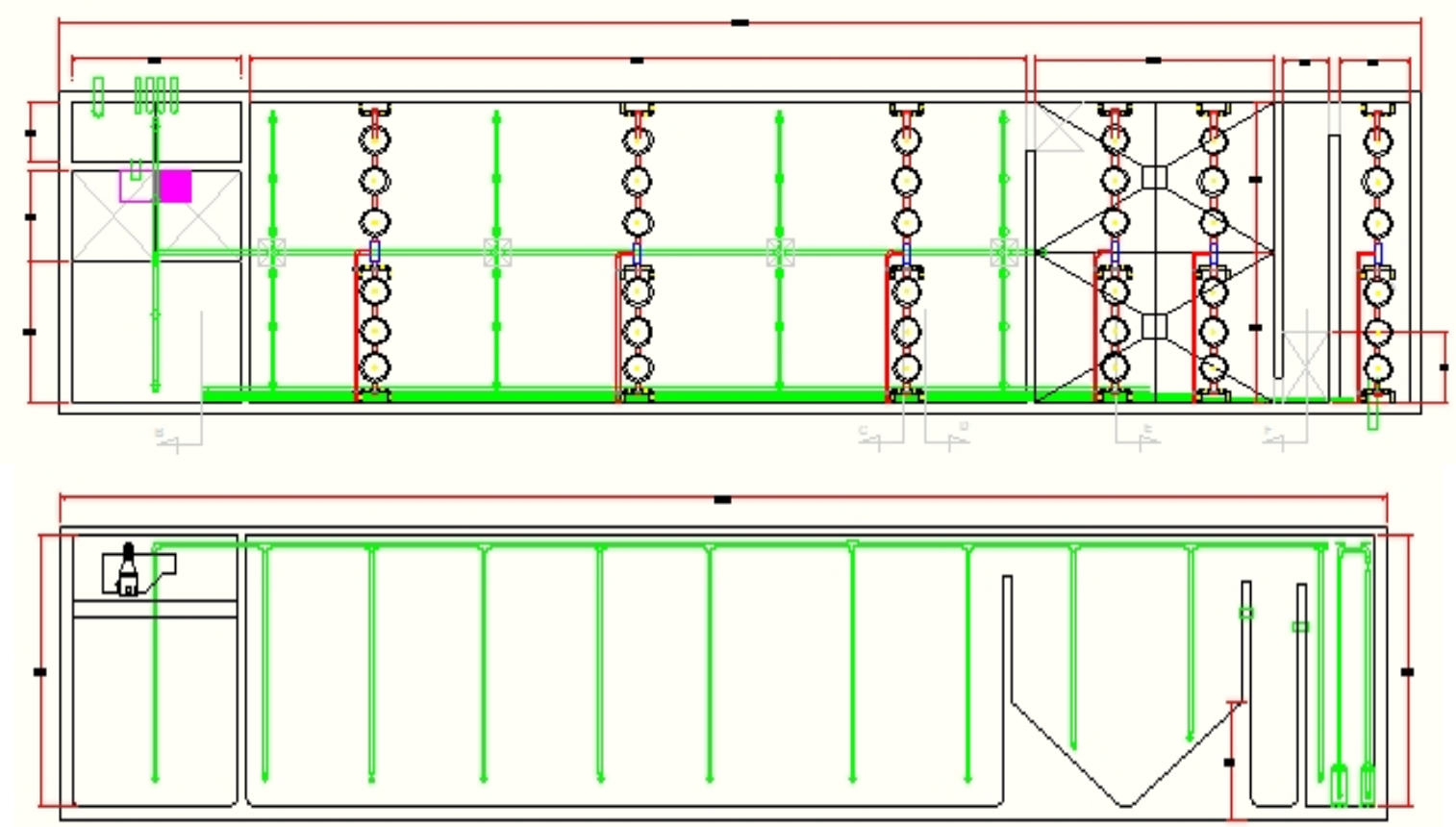

Gambar F : Modifikasi Reaktor Lumpur Aktif. 